\title{
Estratégia de inovação e modelo de gestão: 0 caso de uma pequena empresa produtora de cachaça artesanal
}

Frederico Andreis Beneli Donadon ${ }^{1}$

David Santos ${ }^{1}$

${ }^{1}$ Universidade Estadual Paulista "Júlio de Mesquita Filho" 


\section{ESTRATÉGIA DE INOVAÇÃO E MODELO DE GESTÃO: O CASO DE UMA PEQUENA EMPRESA PRODUTORA DE CACHAÇA ARTESANAL}

Resumo: A capacidade de inovar é um dos fatores críticos à competitividade e longevidade empresarial, segundo a literatura. No entanto, há uma lacuna teórico-empírica de estudos quanto à forma como as pequenas e médias empresas convergem suas estratégias de inovação ao modelo de gestão. Esta pesquisa se posiciona nesse gap teórico, cujo objetivo é analisar o alinhamento da estratégia de inovação ao modelo de gestão de uma pequena empresa produtora de cachaça artesanal. O estudo de caso foi realizado por abordagem qualitativa, com o uso da análise de conteúdo, suportada pela análise de similitude e frequência de palavras. Os resultados viabilizados a partir da ferramenta $B M C$-Canvas e validados pela análise de similitude indicam que o alinhamento entre o modelo de negócio e a inovação insere-se de forma estratégica e estruturada na empresa, com reflexos na capacidade de atender novas demandas por meio de lançamento de novos produtos de maior valor agregado.

Palavras-chave: Empreendedorismo. Gestão Estratégica. IRAMUTEQ. Pequenos Negócios.

\section{Introdução}

A sobrevivência/mortalidade das MPEs (Micro e Pequenas Empresas) tornou-se temática recorrente nas instituições e órgãos com trânsito pelo universo dos pequenos negócios no país, de forma mais relevante pelo Sebrae (Serviço Brasileiro de Apoio às Micro e Pequenas Empresas), que periodicamente publica relatórios, com base em dados disponibilizados pela Secretaria da Receita Federal (SRF).

Em seu mais recente relatório sobre o assunto (Outubro, 2016), não obstante o cenário ali exposto, repleto de desafios, o Sebrae destaca o aumento do percentual de sobrevivência média das empresas com até dois anos, criadas entre 2008 e 2012, de 54,2\% (empresas criadas em 2008) para 76,6\% (empresas criadas em 2012).

Dentre os fatores elencados pelo referido órgão como geradores do avanço significativo no período, entre 2008 e 2014, destacam-se: a expansão dos Micro Empreendedor Individual (MEI) e o aumento do Produto Interno Bruto (PIB) brasileiro no período - no caso ambos favorecidos pelo aumento da rendimento médio real dos trabalhadores, em especial do salário mínimo, a tendência à redução média das taxas de juros, a queda da taxa de desemprego na economia e a melhora da legislação em favor dos Pequenos Negócios.

O relatório de outubro/2016 expõe ainda pesquisa aplicada a 2.006 empresas, ativas e inativas, com o objetivo de ratificar os fatores determinantes da sobrevivência/mortalidade especificados nos relatórios anteriormente publicados. A esse respeito, a devolutiva da referida pesquisa destaca complexidades principalmente quanto ao processo de gestão do negócio, conforme especificações a seguir, sobre as empresas não sobreviventes:

[...] Há uma proporção maior de empresários que estavam desempregados antes de abrir o negócio, que tinham pouca experiência no ramo, que abriram o negócio por 


\begin{abstract}
necessidade e/ou exigência de cliente/fornecedor e não porque identificaram uma oportunidade e/ou que desejavam ter o próprio negócio, que tiveram menos tempo para planejar o negócio, que não conseguiram negociar com fornecedores nem conseguiram empréstimos em bancos, que não aperfeiçoavam seus produtos/serviços, que não investiam na capacitação da mão-de-obra, que inovavam menos, que não faziam o acompanhamento rigoroso de receitas e despesas, que não diferenciavam seus produtos e que não investiam na sua própria capacitação em gestão empresarial (SEBRAE, outubro 2016,p. 53; grifo nosso).
\end{abstract}

Depreende-se do contexto supracitado que a competitividade das pequenas e médias empresas perpassa pela formalização de um processo de gestão com estratégias claras para o negócio, incluindo a inovação e o investimento em mão-de-obra. Esses apontamentos alinhamse a outros estudos empíricos no exterior, notadamente no que tange a empresas de cunho familiar (HUGHES et al., 2017) e no Brasil, incluindo setores específicos como o da cachaça artesanal (BORGES; TAKEMOTO, 2019).

Dados mais recentes do IBGE (2017) reportam para um total de 467 empresas industriais de bebidas no Brasil com mais de 30 funcionários, sendo que destas, 48 são destinadas à produção de bebidas destiladas. No entanto, levantamento realizado em 2018 pelo Ministério da Agricultura, Pecuária e Abastecimento (MAPA) constatou um total de 951 produtores de cachaça em âmbito nacional, o que sugere a predominância de pequenos e médios produtores neste segmento muito peculiar ao país (ANDRADE et al., 2018; MAPA, 2019).

Empreendedores e empresas direcionadas à produção de cachaça no Brasil têm sido alvo de diferentes estudos empíricos voltados, por exemplo, à gestão tecnológica da produção (MARTINS, 2018), à inovação tecnológica e comportamento empreendedor (BORGES; TAKEMOTO, 2019), ao processo de formalização da cachaça (PINOTTI; VERDI; JERONIMO, 2018), dentre outros.

Não obstante o sensível aumento na literatura de pesquisas sobre a cachaça, denota-se uma lacuna ainda não explorada nos estudos empíricos em relação à forma como as empresas nessa atividade, especialmente as pequenas e médias, convergem suas estratégias de inovação ao modelo de gestão (PAIVA et al., 2018).

Nagano, Stefanovitz e Vick (2014, p.163) corroboram a concepção exposta ao observarem que, em relação às organizações em geral, há latente necessidade de pesquisas que aprofundem temas como estratégia, governança dos processos, gestão de pessoas e inovação, dentre outros, sob a óptica dos desafios que as organizações enfrentam para inovar. Referidos autores registram "a carência de trabalhos empíricos que analisem a realidade das práticas propostas no mundo organizacional, em especial no Brasil" e propõem "abordagens mais sistêmicas para o entendimento e gerenciamento do processo inovador".

Desta forma, essa pesquisa surgiu a partir da seguinte questão norteadora: "como uma pequena empresa produtora de cachaça pode alinhar suas estratégias de inovação ao seu modelo de gestão?" Compreender como pequenas e médias empresas organizam seus recursos (tangíveis e intangíveis) de modo a viabilizar estratégias de inovação endereçadas ao seu modelo de negócios pode permitir novos entendimentos sobre as possibilidades de aplicações de pressupostos teóricos na área de gestão da inovação.

Em adição, discutir essa temática no segmento de cachaça artesanal é relevante para o país, pois apesar da tradição do Brasil na produção de cachaça, esse produto é pouco 
desenvolvido internacionalmente no segmento de destilados com receita anual de exportação inferior a U\$ 60 milhões, concentrado em poucas empresas (AGÊNCIA BRASIL, 2019).

Por isso, discutir empiricamente os processos de gestão que permitem o alinhamento entre estratégias de inovação e o modelo de gestão da empresa pode contribuir para o aumento da competitividade do setor ainda marcado pela informalidade e baixa profissionalização dos pequenos e médios "engenhos de cachaça" no Brasil (MARTINS et al., 2018; IBRAC Instituto Brasileiro da Cachaça, 2018).

Para alcançar o objetivo proposto, este estudo está organizado em mais quatro seções, a partir desta introdução. A segunda seção apresenta os fundamentos teóricos que embasam a pesquisa; na sequência são apresentados os Materiais e Métodos utilizados para coleta, análise, tratamento e validação das informações compiladas nas entrevistas semiestruturadas. Os resultados e discussões frente ao objetivo do estudo integram a quarta seção, complementada pelas considerações finais na quinta seção. As referências utilizadas estão elencadas ao final do trabalho.

\section{Referencial Teórico}

Profissionais de mercado e acadêmicos têm dispensado especial atenção às atividades inovativas nas organizações, já que a partir do final do século XX e início do atual, a competição global tem evidenciado a inovação como um componente essencial para a dinamicidade da economia, sustentabilidade dos negócios e desenvolvimento social de comunidades, cidades, regiões e países (GUNDAY et al., 2011; WITTAYAPOOM, 2014; ZHANG; WU, 2018).

Nesse cenário, estudos contemporâneos têm exaltado a relevância de um contexto organizacional favorável à criação, uso e compartilhamento de informações, ideias e conhecimentos mais condizentes com a demanda e que possam levar a organização inovativa a alcançar maior competitividade do que empresas que não inovam (WU, 2011; CHENG; CHANG; LI, 2013, HUGHES et al., 2017).

Para Tidd, Bessant e Pavitt (2008), na prática da inovação deve-se relevar a habilidade de estabelecer relações, detectar oportunidades e tirar proveito das mesmas. Em relação às inovações em tecnologias, o processo de desenvolvimento interno depende essencialmente da forma de gestão das empresas (DOSI, 1988). A combinação complexa e dinâmica de elementos humanos, organizacionais e tecnológicos exige procedimentos bem articulados de conhecimentos tácitos e explícitos, cujos riscos fazem da inovação um intrincado desafio de gestão (NAGANO; STEFANOVITZ; VICK, 2014; RAMOS; ZILBER, 2015).

Nesse contexto, teóricos ratificam as inovações com foco no desenvolvimento tecnológico como necessárias, mas advertem para os grandes investimentos requeridos, o que remete à demanda por parte das empresas de um modelo de gestão adequado, que possibilite inclusive sustentabilidade dessa estrutura orientada à inovação (VON HIPPEL; OGAWA; DE JONG, 2011; ZHAO; PAN; CHEN, 2018).

Os referenciais expostos evidenciam que a ocorrência efetiva da inovação nas organizações requer gestores conscientes quanto à importância de inovar no cenário competitivo vigente, que assimilem o conceito de inovação e estejam aptos a entender a dinâmica do processo inovativo (VARANDAS; SALERNO; MIGUEL, 2014; BREM; VIARDOT, 2017). 
Além das premissas anteriormente especificadas, um dos fatores essenciais para o sucesso inovativo em uma organização é a definição clara da estratégia de inovação adotada, que deve estar alinhada aos objetivos da organização, ao modelo de gestão da mesma e à visão de futuro, em perspectiva considerada, na atualidade, como uma abordagem central no que diz respeito à estratégia empresarial. Assim, empresas com objetivos definidos quanto à sobrevivência e crescimento procuram adaptar suas estratégias tecnológicas à competição do mercado, quando da introdução de um novo produto ou processo (FREEMAN; SOETE, 1997).

No Brasil, os pequenos negócios gradativamente têm incorporado a busca pela inovação contínua em seus processos, através de programas como, por exemplo, o ALI - Agentes Locais de Inovação, consolidado a partir de 2010 pelo Sebrae em abrangência nacional, em parceria com o Conselho Nacional de Desenvolvimento Científico e Tecnológico - CNPq. Referido projeto tem como principal direcionamento o incentivo à estratégia de competitividade e excelência na gestão das MPEs, em relação à capacidade dos dirigentes de avaliar e implantar ideias próprias ou de terceiros, alicerçados por colaboradores capacitados, de forma a obter ganhos de eficiência e produtividade.

\section{Procedimentos Metodológicos}

Esta pesquisa tem abordagem metodológica pautada nos estudos qualitativos, de natureza aplicada, por meio do estudo de caso único, desenvolvido através das seguintes etapas: reconhecimento da rotina do processo produtivo com o intuito de evidenciar a dinâmica tecnológica e impactos das estratégias de gestão e inovação, com destaque para as etapas de maior relevância na empresa a partir da análise do modelo de gestão praticado (mediante autorização prévia, face ao sigilo industrial exigido), entrevista pessoal (semiestruturada) com os envolvidos no processo e coleta de dados (análise de documentos e observação visual). Para complementação de registros relevantes recorreu-se também a dados da empresa disponibilizados no site da mesma.

O Quadro 1 traz a estrutura das ferramentas utilizadas para coleta, análise, exploração, tratamento e validação dos dados obtidos.

Quadro 1. Quadro-Resumo das Ferramentas Utilizadas para Coleta e Validação dos dados

\begin{tabular}{|l|l|l|}
\hline Base Conceitual & Business Model Canvas-BMC & $\begin{array}{l}\text { Software de Análise Textual } \\
\text { IRAMUTEQ }\end{array}$ \\
\hline Autoria & $\begin{array}{l}\text { Business Model Generation } \\
\text { (Osterwalder; Pigneur, 2010). }\end{array}$ & $\begin{array}{l}\text { Interface de R pour les Analyses } \\
\text { Multidimensionnelles de Textes et } \\
\text { de Questionnaires (Ratinaud, 2009). }\end{array}$ \\
\hline $\begin{array}{l}\text { Dimensónes } \\
\text { Analisadas }\end{array}$ & $\begin{array}{l}\text { Parceiros; Atividades; Recursos; Proposta de } \\
\text { Valor; Relacionamento; Canais; Segmentos de } \\
\text { Cliente; Fontes de Receita e Estrutura de Custo. }\end{array}$ & - Análise de Similitude \\
\hline
\end{tabular}

Fonte: Dados da Pesquisa (2019).

A partir do norteamento da metodologia e das ferramentas de coleta e validação dos dados, o presente estudo ateve-se ao caso estudado. A empresa envolvida foi selecionada por critérios intencionais, dentre outras MPEs com histórico de sistema de gestão inovativo e inseridas em setores que apresentavam inovações tecnológicas, melhorias substanciais em produtos ou processos ou ainda modelos de gestão que priorizavam as estratégias de inovação 
no ambiente organizacional. A única exigência em relação à empresa selecionada foi quanto ao sigilo industrial, razão pelo qual a mesma está identificada no presente estudo apenas como Empresa Delta, conforme dados subsequentes:

Quadro 2. Quadro-resumo do Perfil da Empresa Selecionada

\begin{tabular}{|l|l|}
\hline \multicolumn{2}{|c|}{ Empresa Delta } \\
\hline Características do cenário pesquisado & $\begin{array}{l}\text { Tradicional alambique de cachaça (engenho de açúcar e } \\
\text { derivados do final do século XX, há quase } 80 \text { anos em } \\
\text { atividade, gerido por várias gerações da mesma família. }\end{array}$ \\
\hline Porte & Pequeno \\
\hline Fundação & 1943 \\
\hline Produto & Cachaça artesanal \\
\hline Gestão & $\begin{array}{l}\text { Empresa familiar gerida pelo pai e filhos (sócios } \\
\text { proprietários) }\end{array}$ \\
\hline $\boldsymbol{N}^{\boldsymbol{o}}$ de Funcionários & 04 empregados fixos, mais familiares e agregados. \\
\hline Mercado Consumidor & Nacional \\
\hline
\end{tabular}

Fonte: Dados da Pesquisa (2019).

A opção pelo estudo empírico no engenho de cachaça justifica-se porque, na atualidade, esse produto tem se destacado como tendência alternativa em que predominam as MPEs, cujos empreendedores têm enfatizado a diferenciação de produtos através de maior valor agregado, como uma das formas de competitividade.

Pelo fato da temática envolvida ser de nível estratégico à organização, para melhor viabilidade das entrevistas, utilizou-se como fonte de informação e pesquisa os principais envolvidos na empresa, num total de quatro, conforme segue: o gestor comercial e responsável pela área de inovação (filho do proprietário), o proprietário (pai), o empregado responsável pela produção e outros (demais familiares e funcionários envolvidos no cotidiano da organização). Planejadas e executadas em visitas previamente agendadas na empresa, conforme Quadro 3, as entrevistas geraram dados internos expressivos, a partir da aplicação de questionários semiestruturados, com base nas dimensões do BMC-Canvas.

Quadro 3. Resumo das Entrevistas - Coleta de Dados Presenciais - Empresa Delta

\begin{tabular}{|c|c|c|c|c|c|c|}
\hline Entrevistado & Cargo & Formação & Experiência & Entrevistas & Período & Temática \\
\hline [E1] & $\begin{array}{l}\text { Gestor } \\
\text { Comercial }\end{array}$ & Agronomia & 10 anos & 01 entrevista & $\begin{array}{l}2^{\circ} \text { semestre } \\
2018 \text { (Out.) }\end{array}$ & $\begin{array}{l}\text { BMC - } \\
\text { Canvas }\end{array}$ \\
\hline [E2] & Proprietário & $\begin{array}{l}\text { Não } \\
\text { especificada }\end{array}$ & 40 anos & 01 entrevista & $\begin{array}{l}1^{\circ} \text { semestre } \\
2019 \text { (Mar.) }\end{array}$ & $\begin{array}{l}\text { BMC - } \\
\text { Canvas }\end{array}$ \\
\hline [E3] & $\begin{array}{l}\text { Produçãoo } \\
\text { (responsável) }\end{array}$ & $\begin{array}{l}\text { Não } \\
\text { especificada }\end{array}$ & 08 anos & 01 entrevista & $\begin{array}{l}1^{\circ} \text { semestre } \\
2019 \text { (Mar.) }\end{array}$ & $\begin{array}{l}\text { Processo } \\
\text { Produtivo }\end{array}$ \\
\hline [E4] & $\begin{array}{l}\text { Demais } \\
\text { familiares }\end{array}$ & $\begin{array}{l}\text { Não } \\
\text { especificada }\end{array}$ & 20 anos & 01 entrevista & $\begin{array}{l}1^{\circ} \text { semestre } \\
2019 \text { (Mar.) }\end{array}$ & $\begin{array}{l}\text { Processo } \\
\text { Produtivo }\end{array}$ \\
\hline
\end{tabular}

Fonte: Dados da Pesquisa (2019). 
As estratégias de levantamento de informações com base em entrevistas, observação in loco e análise de documentos internos previamente autorizados são mecanismos que possibilitaram entregar aos resultados um maior nível de imparcialidade, pois são fontes de informação de diferentes atores da empresa, cuja triangulação permitiu uma análise por terceira parte independente e, no caso de assimetrias ou conflitos, estes foram explorados tanto no sentido de melhor compreendê-los ou como forma de evidenciar dissociações entre discurso e prática.

\section{Análise e Discussão dos Resultados}

Os resultados da pesquisa empírica são apresentados sequencialmente. Em razão da quantidade de dados qualitativos coletados, procurou-se estruturar a seção conforme os objetivos do estudo.

\subsection{Resultados das Entrevistas para o Modelo de Gestão, Estratégia e Capacidade de Inovar}

O Canvas, enquanto ferramenta de gerenciamento estratégico, tem sido muito utilizado no empreendedorismo por permitir o esboço do modelo de negócio praticado de forma simples, rápida e prática. É conhecido também pelo nome da obra original "Business Model Generation" (Alexander Osterwalder; Yves Pigneur, 2010). Na sequência, o resultado da aplicação do Canvas:

Quadro 4. Quadro-resumo: devolutiva do Canvas da empresa Delta

\begin{tabular}{|l|l|}
\hline Dimensões & \multicolumn{1}{c|}{ Diagnóstico } \\
\hline $\begin{array}{l}\text { Segmentos de } \\
\text { clientes }\end{array}$ & $\begin{array}{l}\text { A empresa apresenta um modelo de negócio focado em mercado } \\
\text { consumidor de clientes com perfis e demandas similares, alinhados com a } \\
\text { proposta de valor da mesma. Dentre os consumidores do produto da } \\
\text { empresa estão os apreciadores da cachaça e donos de bares e restaurantes. }\end{array}$ \\
\hline $\begin{array}{l}\text { Relacionamento } \\
\text { com clientes }\end{array}$ & $\begin{array}{l}\text { O relacionamento com clientes é bastante informal; a empresa coloca as } \\
\text { estratégias de relacionamento como fator relevante para a fidelização dos } \\
\text { clientes. O aprendizado a partir da interação e envolvimento dos usuários } \\
\text { no processo promove a agregação de valor ao produto e se reverte em } \\
\text { vantagem competitiva e de rentabilidade para a empresa. }\end{array}$ \\
\hline Canais & $\begin{array}{l}\text { Há participação dos clientes no processo de realização da proposta de } \\
\text { valor da empresa através de canais que, dentre outras especificidades, } \\
\text { ampliam o conhecimento sobre o produto oferecido pelo modelo de } \\
\text { negócios da empresa. Usualmente são utilizados pela empresa os canais } \\
\text { físicos (vendas diretas aos clientes e representantes de vendas junto ao } \\
\text { comércio varejista) e, mais recentemente o canal virtual, com criação de } \\
\text { site próprio aberto à aquisição dos vários produtos da empresa. }\end{array}$ \\
\hline Propostas de valor & $\begin{array}{l}\text { A empresa procura repassar o valor criado sobre o produto para os clientes } \\
\text { através da diversificação da produção como aposta para se manter } \\
\text { dinâmica, competitiva e com crescimento de mercado. Embora tímida, a } \\
\text { proposta de valor primordial da empresa envolve a inovação. O feedback } \\
\text { sobre um valor percebido pelo cliente pode auxiliar a empresa na decisão } \\
\text { sobre qual a melhor proposta de valor a ser oferecida, já que preço, }\end{array}$ \\
\hline
\end{tabular}




\begin{tabular}{|l|l|}
\hline Recursos-chave & $\begin{array}{l}\text { praticidade e novidade são valores altamente considerados pela gestão } \\
\text { comercial da empresa. }\end{array}$ \\
\hline $\begin{array}{l}\text { Um recurso-chave de relevância para a empresa é o recurso físico que } \\
\text { envolve a instalação e manutenção de todo maquinário envolvido, com } \\
\text { vistas inclusive à melhoria do cenário (lugar onde se encontra o alambique }\end{array}$ \\
e que recebe muitos clientes que preferem pegar a cachaça in loco). Outros \\
recursos intelectuais como patentes e direitos autorais (grande \\
complicador em relação ao uso da expressão "sertaneja" e "artesanal" na \\
cachaça, um uso genérico, mas que alguns alegam deter o direito de \\
propriedade de uso exclusivo dessas palavras), além de busca por recurso \\
financeiro como capital e linhas de crédito fazem parte do quotidiano da \\
empresa.
\end{tabular}

Fonte: Elaboração própria a partir dos dados compilados (2019).

Pelos relatos e observação in loco, a empresa destina recursos intangíveis às competências incorporadas em seus colaboradores e no grupo familiar, recursos esses responsáveis pela capacidade inovativa, que engloba todo o corpo de conhecimentos tácitos e explícitos acumulados e se reverte como ativos de conhecimentos codificados nos registros internos da organização, sejam eles apropriáveis ou não, sob a forma de propriedade intelectual 
(Quadros, 2008; Stefanovitz; Nagano, 2014), conforme estrutura da capacidade de inovar da empresa Delta, exposta no Quadro 05 subsequente:

\title{
Quadro 05 -Fatores Determinantes da Capacidade/Estrutura para Inovar na empresa
}

\begin{abstract}
Cultura de Inovação da empresa Delta: promoção da busca pela inovação como valor da organização; Compartilhamento de conhecimentos e serviços entre colaboradores (não há divisão de tarefas, em comportamento típico de empresa de gestão e mão de obra familiar);

Empenho voltado não só para a excelência quanto ao produto produzido, mas também à aparência do alambique, com direcionamento para outros eixos econômicos como o turismo rural e utilização da cachaça para a produção de licores e outros derivados.

Estrutura intraorganizacional adequada para que o trabalho multifuncional ocorra com fluidez através da prática de interface entre modelo de gestão, estratégia e táticas no cenário da organização, voltados à viabilização da melhoria no processo produtivo e controle de qualidade do produto elaborado através de Manual de Boas Práticas de Fabricação. Nesta direção, há que se destacar a atitude especial de oferta do produto, além do convencional, na embalagem de vidro, também na embalagem plástica (com laudo que atesta que o material pode ser usado para bebida alcoólica), ao envasar a cachaça e a caipirinha, com vistas à prevenção de acidentes ao longo do manuseio e transporte e no ato do consumo.
\end{abstract}

Significativo relacionamento com instituições de pesquisa, como universidades e outros, via internalização/sistematização de subsídios relacionados à inovação de produto, processo e gestão organizacional.

Legalização perante o MAPA (Ministério da Agricultura, Pecuária e Abastecimento) do estabelecimento e de toda linha de produtos, em situação que permite a aquisição e/ou desenvolvimento de tecnologias, maior acesso à informação e recursos, além de ampliar aproximação das estratégias de cooperação e das ações das instituições envolvidas com a produção.

Estrutura voltada à busca de oportunidades para diversificação do destino da produção, em apostas como venda direta ao consumidor, conquista de mercado em outras regiões, estados ou até mesmo no exterior - este último um plano a curto prazo da empresa), frente à incerteza do mercado em relação à falta de regularidade nos pedidos (a cachaça é um produto condicionado a vendas sazonais como festa junina e festas de final de ano, havendo, assim, a necessidade da empresa estruturar-se para os períodos de menor consumo.

Logística de produção e envio dos produtos facilitada e agilizada devido à localização do alambique em município pertencente ao polo regional centro norte do estado de São Paulo.

Empenho na superação da concorrência; construção periódica de novo portfólio de produtos, dentre eles a "Cachaça Sertaneja PRATA" (que pode ser consumida como saiu do alambique ou "descansada" em tonéis de madeira de amendoim, para preservação da cor "branca" e diminuição da acidez, o que a torna especial para a preparação de coquetéis e batidas como a "caipirinha"); a produção da "Cachaça Sertaneja OURO" (que, "descansada" em tonéis de madeira de carvalho, obtém a coloração "dourada", amadurece e aumenta o grau de excelência, sem perder a essência); a produção recente da cachaça "nobre", a "Cachaça Sertaneja PREMIUM BIDESTILADA" (que passa por duas destilações consecutivas e é envelhecida por no mínimo 1 ano em cartolas de carvalho europeu de 200 a 500 litros, em processo que bonifica o paladar, "arredonda" a cachaça, tornando-a mais especial e genuína).

Colaboração com parceiros externos em contexto que promove a troca contínua de informações tecnológicas e mercadológicas, em capacidade real da empresa de aprender com o ambiente e se 
manter atualizada (diferentemente da cachaça industrial que tem sua lucratividade no ganho de escala, a cachaça artesanal insere-se atualmente em um nicho de mercado bastante refinado e exigente, do qual fazem parte aqueles que realmente apreciam degustar a bebida, em situação que requer aprimoramento contínuo do produto oferecido).

Perfil empresarial dinâmico, bastante instruído, com grandes ambições e grande visão de mercado do principal gestor à frente da Empresa Delta (filho do proprietário), com características evidenciadas como iniciativa, espírito de inovação, pró-atividade, capacidade para resolução de conflitos, liderança, perfil colaborativo, conhecimento de fatores externos como Concorrência e Análise de Preço, dentre outras, que culminam em uma gestão descentralizada, aberta, flexível, com foco na dinâmica incremental do principal produto, a cachaça.

Para um alinhamento com as acepções expostas, a agroindústria passou a reduzir o impacto dos modos de produção no ambiente, reforçar a resiliência da natureza e utilizar os recursos naturais de maneira mais eficiente e responsável, dispondo de local apropriado para a deposição dos resíduos, de forma a não atrair insetos, roedores e outros, bem como em relação à preservação do meio ambiente, com vistas a considerar a eco inovação como um fator de inovação que se traduz em avanços importantes na direção do desenvolvimento sustentável.

Fontes: Elaboração própria a partir de dados compilados na empresa e em Quadros (2008); Chen, Tsou e Huang (2009); Stefanovitz e Nagano (2014).

\subsection{Validação dos Resultados via Software IRAMUTEQ}

Por se adequarem mais aos objetivos propostos, as modalidades selecionadas pelo software Iramuteq para o presente estudo foram a "Análise de Similitude" e por "Nuvem de Palavras", expostas na sequência.

\subsubsection{Análise de Similitude sobre os Resultados da Empresa Delta}

A partir dos vocábulos mais citados ao longo dos depoimentos e entrevistas, o software IRAMUTEQ selecionou um universo de 156 palavras, sendo "cachaça" a que apresentou maior fator repetitivo (pronunciada 75 vezes ao longo dos discursos registrados) e "maior", a de menor frequência (pronunciada apenas 03 vezes pelos respondentes).

Por questão de concisão, optou-se pelo registro das palavras com maior frequência repetitiva, até a classificação 10, intencionalmente expostas em ordem decrescente. $\mathrm{O}$ intuito é de se relevar o aspecto classificatório em relação à força de expressão das palavras nas coocorrências e correlações dos discursos dos entrevistados. O Quadro 6, na sequência, expõe de forma sucinta a classificação dos vocábulos e discursos anteriormente mencionados: 
Quadro 6. Quadro-Resumo Classificatório dos Vocábulos e Discursos - Empresa Delta

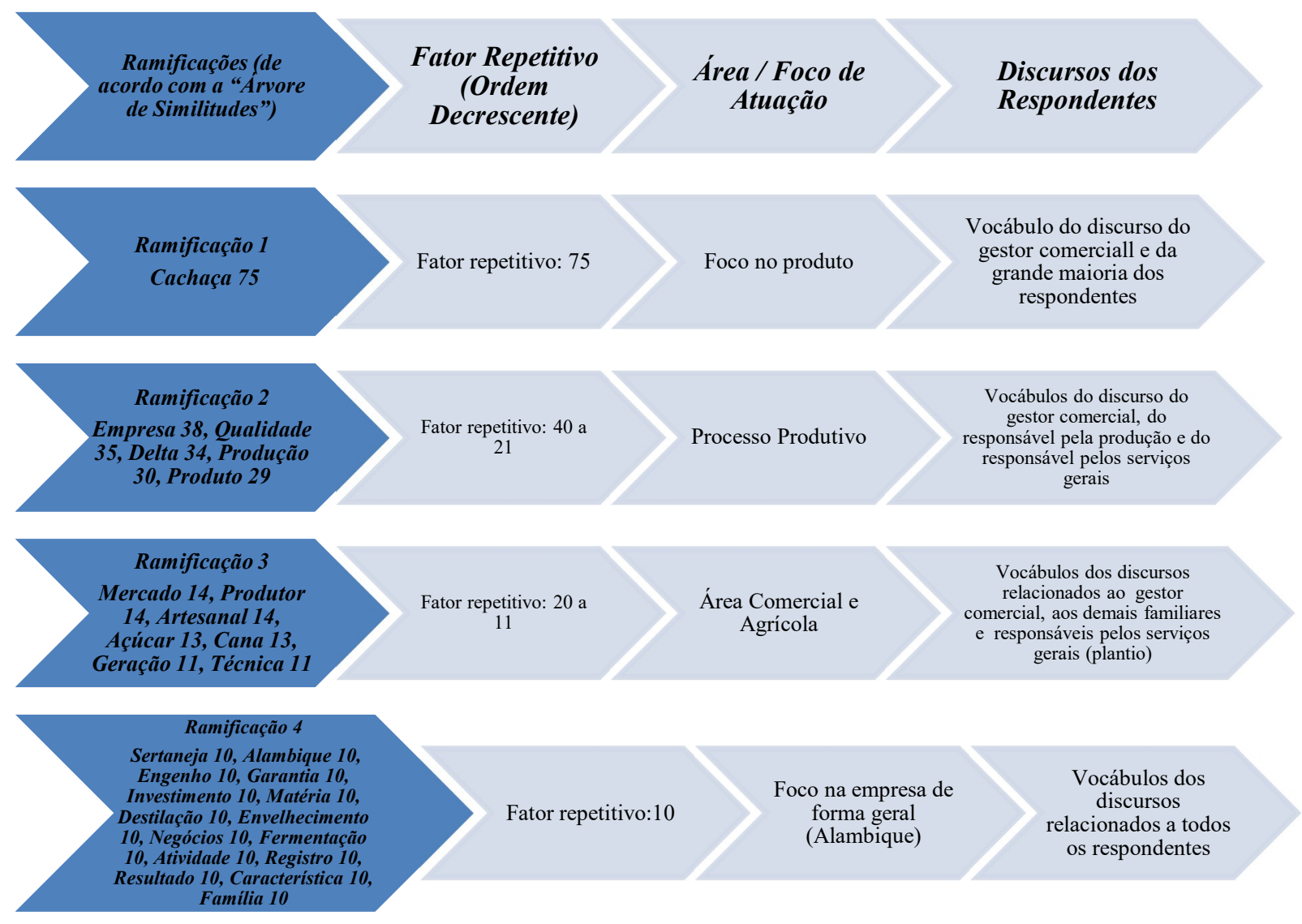

Fonte: Dados da Pesquisa (2019).

Conforme Quadro 6, verificou-se que, a partir da ramificação 1, destacam-se sequencialmente os seguintes vocábulos: cachaça; empresa, qualidade, Delta, produção, produto, mercado, produtor, artesanal, açúcar, cana, geração, técnica, sertaneja, alambique, engenho, garantia, investimento, matéria, destilação, envelhecimento, negócios, fermentação, atividade, registro, resultado, característica e família, todos eles voltados à capacidade tecnológica de inovação em produto e processo, qualidade técnica e resultados em relação à estrutura e gestão da inovação na empresa pesquisada, em contexto que valida o resultado anteriormente exposto no Canvas da referida organização.

Na sequência, o software Iramuteq produziu a "Análise de Similitude "(Fig. 1), que estampa a imagem em cores processada através dos indicadores estatísticos das inter-relações entre os vocábulos destacados no Quadro 6, anteriormente exposto: 
Figura 1. Resultado da "Análise de Similitude” da empresa Delta, gerada a partir do Quadro 6

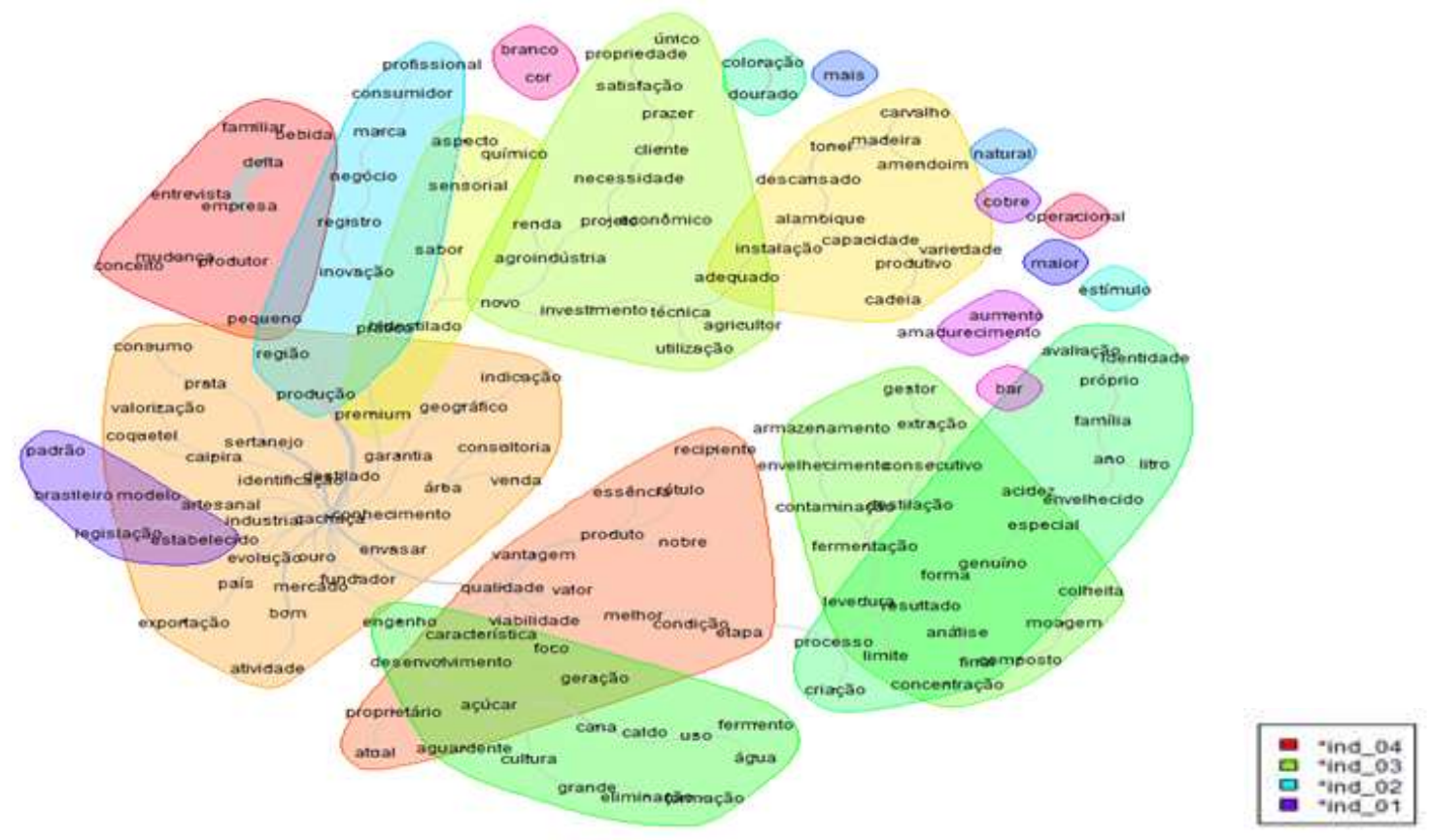

*Ind: Indivíduos entrevistados: E1 a E4.

Fonte: Dados da Pesquisa (2019).

O Quadro-Resumo 7 subsequente auxilia na identificação dos respondentes na figura 1, via concentração de cores:

Quadro 7. Quadro-Resumo de Identificação dos Respondentes por Cor Representativa-

\begin{tabular}{|l|l|l|}
\hline Entrevistado & Atuação & Cor representativa na figura 1 \\
\hline [E1] & Gestor Comercial (filho) & $\begin{array}{l}\text { Cor predominante roxo, com trânsito pelas demais } \\
\text { nuances expostas. }\end{array}$ \\
\hline [E2] & Proprietário (pai) & $\begin{array}{l}\text { Cor predominante azul, em suas várias tonalidades, } \\
\text { com trânsito pelas demais nuances expostas. }\end{array}$ \\
\hline [E3] & $\begin{array}{l}\text { Responsável pela produção } \\
\text { (empregado) }\end{array}$ & $\begin{array}{l}\text { Cor predominante verde, com trânsito pelas demais } \\
\text { nuances expostas. }\end{array}$ \\
\hline$[$ E4] & Demais familiares e agregados & $\begin{array}{l}\text { Cor predominante vermelho claro/rosa, com } \\
\text { trânsito pelas demais nuances expostas. }\end{array}$ \\
\hline
\end{tabular}

Fonte: Dados da Pesquisa (2019).

O resultado da Análise de Similitude (Figura 1), identificado no Quadro-Resumo de Identificação dos Respondentes (Quadro 7), revela os discursos com maior representatividade no corpus textual temático, a partir da concentração de cores em áreas/setores principais de atuação da empresa. A evidência de discursos com significados demarcados em cada um dos campos de cores traz indicação da conexidade entre pessoas e ideias relacionadas entre si e sinaliza a comunicação e a interdependência entre as diversas áreas da empresa, considerando 
inclusive o fato de ser uma agroindústria familiar, sem divisão específica de tarefas na gestão praticada.

A Figura 1 sugere que os vocábulos da devolutiva do gestor principal (filho) transitam por praticamente todo o campo de cores, o que permite validar o anteriormente exposto no resultado do BMC-Canvas da empresa em relação às características de liderança voltadas a resultados do gestor principal na organização e a gestão participativa em ambiente de inovação e alinhamento estratégico com o modelo de negócio praticado. Os discursos expostos na Análise por Similitude permitem ratificar a capacidade gestora da empresa Delta na busca por inovações em produto, de forma mais acentuada, além dos demais focos em processo, estratégia e capacidade/estrutura para inovar.

\subsubsection{Nuvem de Palavras da empresa Delta}

O resultado da Nuvem de Palavras pode ser visualizado na Figura 2 subsequente:

Figura 2. Resultado da "Nuvem de Palavras" da empresa Delta

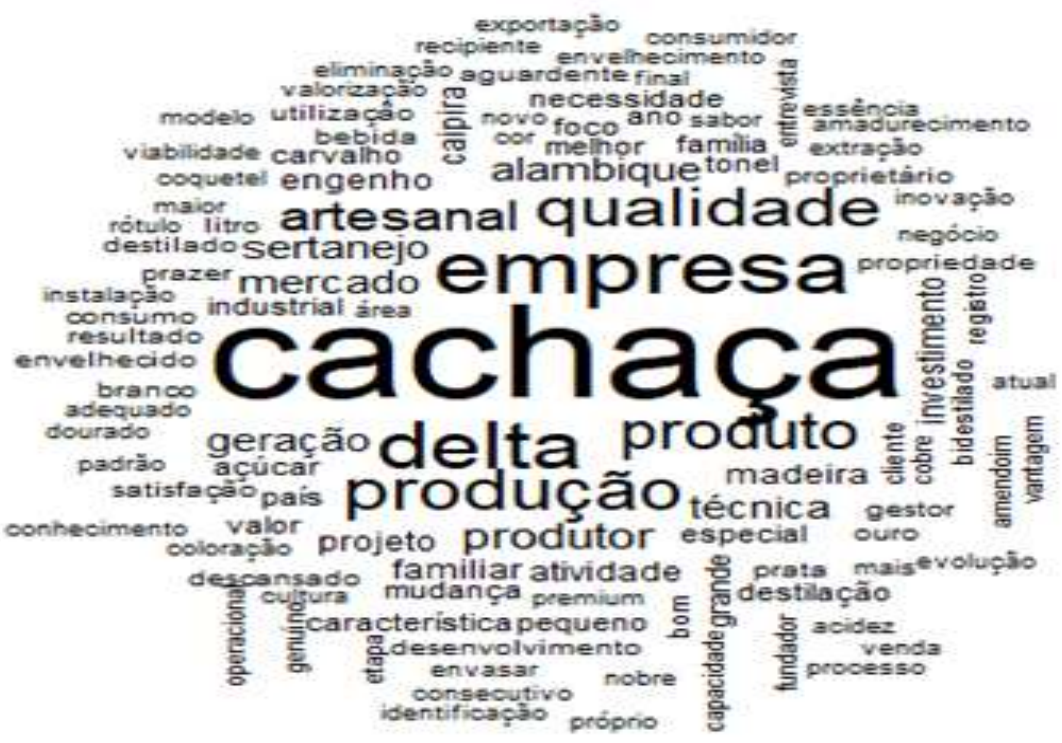

Fonte: Dados da Pesquisa (2019).

O cenário exposto na figura 2 é emblemático ao revelar a relevância do impacto das atividades inovativas para os envolvidos, através do contexto das principais palavras destacadas, dentre elas cachaça, delta, produção, produto, empresa, qualidade e artesanal.

As conexões apresentadas entre os vocábulos na "Análise de Similitudes" e por "Nuvem de Palavras" sinalizam uma vez mais a presença de "discursos" envolvendo o sistema organizacional e de gestão do engenho produtor de cachaça artesanal e permitem validar, num só espaço gráfico, o sensível envolvimento dos entrevistados da organização com os fatores competitivos, tecnológicos e organizacionais envolvidos que, de forma articulada, suportam a estratégia e a capacidade/estrutura para inovar no âmbito da organização pesquisada. 


\section{Considerações Finais}

A motivação do presente estudo está associada ao interesse e necessidade de um melhor entendimento sobre como as empresas, especialmente as pequenas e médias, convergem suas estratégias de inovação ao modelo de gestão, nas atividades e processos estratégicos empreendidos. Para tanto, realizou-se uma pesquisa empírica, de caráter descritivo e abordagem qualitativa, através de estudo de caso em uma pequena empresa produtora de cachaça artesanal.

Infere-se que o objetivo foi alcançado, inicialmente através da revisão bibliográfica, que possibilitou caracterizar as variáveis da pesquisa e buscar orientação quanto à coleta de dados. Posteriormente, através do uso da análise de conteúdo, suportada pela análise de similitude e frequência de palavras, construída a partir do IRAMUTEQ, em cenário de inovação que permitiu validar o alinhamento estratégico no estudo empírico.

Os resultados, viabilizados a partir da ferramenta BMC-Canvas e validados pela análise de similitude, indicam que é no alinhamento com o modelo de negócio praticado que a inovação insere-se de forma estratégica e estruturada na empresa, gerando capacidade de atender novas demandas com o fluxo de lançamento de novos produtos de maior valor agregado.

Denota-se no cotidiano da organização que o objetivo maior voltado à sobrevivência da organização é a ação de agregar valor ao produto oferecido, otimizando principalmente sua qualidade. Nesse processo, o produtor movimenta recursos (capital, tecnologia e conhecimento), de forma a gerar melhorias no processo produtivo, com vistas a criar um produto diferenciado, com maior aceitação e padrão de competitividade no mercado.

$\mathrm{O}$ alinhamento estratégico ocorre também com as inovações incorporadas ao cotidiano da empresa como técnicas diversas de envelhecimento adequado da cachaça, novos formatos de embalagens (com a prevalência pelas transparentes que favorecem a visualização do produto), zelo quanto à gestão de resíduos e à eficiência nas certificações e quanto aos diferentes canais e plataformas de preço.

Quanto à adoção de práticas efetivas de gestão do processo de inovação na empresa, depreende-se que a cultura de inovação incorporada à prática gestora torna-se eficaz na obtenção de ganhos na eficiência e competitividade, contribuindo sobremaneira para o modelo estratégico de gestão da empresa.

A problemática do abastecimento na sazonalidade, dentre outras, tem demandado processos envolvendo dinamismo e mudanças que evidenciam crescimento, possibilidade de desenvolvimento e avanços nas inovações tecnológicas por parte da empresa. A eliminação de desperdício e a redução de custos conduzem à robusta repercussão no faturamento, via ampliação da presença e prestígio no mercado.

Os resultados sinalizam ainda que, além das vantagens econômicas, a atividade de produção de cachaça artesanal pode promover relevantes benefícios sociais, já que detém um significativo potencial de desenvolvimento local, principalmente em função do emprego da mão-de-obra familiar.

O presente trabalho possibilitou identificar áreas passíveis de melhorias na empresa, como por exemplo, a área de $\mathrm{P} \& \mathrm{D}$, que apresenta-se defasada em relação à rede de PD\&I da cachaça (Pesquisa, Desenvolvimento e Inovação Tecnológica voltada à cachaça), definida pelo MAPA (2011). Referida rede de PD\&I norteia os envolvidos a adotarem práticas de estratégias mais assertivas, já que o processo de gerenciamento do investimento no setor é inerente com vistas a manter a competitividade. 
O uso do Software de Análise Textual IRAMUTEQ como ferramenta de apoio à pesquisa para a análise léxica automatizada em Administração de Empresas foi um diferencial no estudo, já que na atualidade referido software é mais comumente utilizado em pesquisas qualitativas produzidas no âmbito dos programas de pós-graduação nas Áreas de Ciências Humanas, Ciências Sociais e da Saúde.

Depreende-se pelo exposto que o estudo trouxe uma implicação teórica importante ao analisar de forma sistêmica a inovação, ou seja, buscar um melhor entendimento sobre como a estratégia de inovação está associada ao modelo de gestão e é amparada pela capacidade de inovar. Acresce-se ao exposto o diferencial do uso de modelos teóricos que se mostram adequados à realidade das agroindústrias em geral e que podem ser explorados em outros estudos.

No tocante ao valor, espera-se que o compartilhamento deste trabalho possa contribuir na disseminação da cultura de inovação e para ampliar a discussão do processo gerencial que articula e alinha as estratégias de inovação ao modelo de gestão, com vistas ao fortalecimento dos pequenos negócios, notadamente em relação à cachaça artesanal, com possibilidade de, eventualmente, extrapolar para outras cadeias do agronegócio.

\section{REFERÊNCIAS}

AGÊNCIA BRASIL. Disponível em http://agenciabrasil.ebc.com.br/economia/noticia/201905/ministerio-da-agricultura-registra-produtores-de-cachaca-e-aguardente. Acesso out.2019.

ANDRADE, Lília Paula et al. Cachaça sob uma Perspectiva Histórica, Cultural e Simbólica. Revista Gestão em Análise, [S.1.], v. 7, n. 2, p. 184201, dez. 2018.

BORGES, A.F; TAKEMOTO, F.N.C. Inovação no setor de cachaça artesanal: estudo de caso. Revista Pensamento Contemporâneo em Administração Rio de Janeiro, v. 13, n. 1, 2019.

BREM, A.; VIARDOT, E. Revolution of Innovation Management, Palgrave Macmillan: United Kingdom, 2017.

CHEN, J., TSOU, H. T.; HUANG, A. Y. Service delivery innovation: antecedents and impact on firm performance. Journal of Service Research, V.12, n.1, 36-55, 2009.

CHENG, C. F.; CHANG, M. L.; LI, C. S. Configural paths to successful product innovation. Journal of Business Research, V. 66, n. 12, p. 2561-2573, 2013.

DOSI, G. The nature of the innovative process. IN: DOSI, G. (org). Technical change and economic theory. Londres: Pinter Publishers, 1988.

FREEMAN, C.; SOETE, L. The economics of industrial innovation. 1. ed. Cambridge: MIT Press, 1997. 
GUNDAY, G.; ULUSOY, G.; KILIC, K.; ALPKAN, L. Effects of innovation types on firm performance. International Journal of Production Economics, V. 133, n. 2, p. 662-676, 2011.

HUGHES, M.; FILSER, M.; HARMS, R.; KRAUS, S.; CHANG, M.L.; CHENG, C.F. Family Firm Configurations for High Performance: The Role of Entrepreneurship and Ambidextery. British Journal of Management, Vol. 00, 1-18, 2017.

IBGE - Instituto Brasileiro de Geografia e Estatística. Rio de Janeiro. Pesquisa Industrial Anual-PIA Produto 2017. https://www.ibge.gov.br/estatisticas/economicas/industria/9044pesquisa-industrial-anual-produto.html? $=\& \mathrm{t}=\mathrm{o}$-que-e. Acesso em nov. 2019.

IBRAC - INSTITUTO BRASILEIRO DA CACHAÇA. Câmara Setorial da Cadeia Produtiva da Cachaça, 2018. http://www.agricultura.gov.br/assuntos/camaras-setoriais tematicas/documentos/camarasetoriais/cachaca/2018/52aro/apresentacao_reuniao_54_camara _abril_2018_para_apresentacao_envio.pdf. Acesso em jun. 2019.

MAPA. Ministério da Agricultura, Pecuária e Abastecimento. Secretaria de Defesa Agropecuária - DAS. A cachaça no Brasil: dados de registro de cachaças e aguardentes. Brasília: MAPA/AECE, 2019.

MARTINS, M. F.; SILVA, N. C.; EURIQUES, R. A. B.; CÂNDICO, G. A. Gestão e Tecnologia em Engenhos Produtores de Cachaça no Brejo da Paraíba-Brasil. Revista Gestão Industrial, Ponta Grossa, v. 14, n. 3, p. 209-230, jul./set. 2018.

NAGANO, M. S.; STEFANOVITZ, J. P.; VICK, T. E. Caracterização de processos e desafios de empresas industriais brasileiras na gestão da inovação. Revista Brasileira de Gestão de Negócios. FECAP - v.16, p. 163-179, 2014.

OSTERWALDER A.; PIGNEUR, Y. Business Model Generation. Booksgooglecom, v. 30, n. 5377, p. 288, 2010.

PAIVA, A. L.; ANDRADE, D. M.; ANTONIALLI, L. M.; BRITO, M. J. Strategic Entrepreneurship: Observations From The Practices of Cachaça Certification.Revista de Administração Mackenzie, v. 19, n. 2, n. 1-24,2018.

PINOTTI, R. N.; VERDI, A. R.; JERONIMO, E. M. Processo de formalização da cachaça de alambique no Estado de São Paulo. Revista Científica ANAP Brasil, [S.1.], v. 11, n. 22, out. 2018.

QUADROS, R. Aprendendo a inovar: padrões de gestão da inovação tecnológica em empresas industriais brasileiras. Unicamp, Relatório de Pesquisa - Padrões de gestão da inovação tecnológica em empresas brasileiras. CNPq, 2008.

RAMOS, A.; ZILBER, S. N. O Impacto do Investimento na Capacidade Inovadora da Empresa. Review of Administration and Innovation - RAI - FEA/USP, v. 12, n. 1, p. 303, 2015. 
RATINAUD, P. Iramuteq: Interface de R pour les Analyses Multidimensionnelles de Textes et de Questionnaires (2009). Disponível em http://www.iramuteq.org. Acesso em Nov. 2018.

SEBRAE - SERVIÇO BRASILEIRO DE APOIO ÀS MICRO E PEQUENAS EMPRESAS (2012). Cachaça artesanal (Séries Estudos Mercadológicos). Relatório completo. p.84, 2012.http://www.bibliotecas.sebrae.com.br/chronus/ARQUIVOS_CHRONUS/bds/bds. nsf/444c2683e8debad2d7f38f49e848f449/\$File/4248.pdf. Acesso agosto, 2019.

(2013). Cadernos de Inovação em Pequenos Negócios: Indústria, V. 1, nº 1, 2013 : Sebrae; CNPq, Brasília/DF. Disponível em http://www.cadernosdeinovacao.com.br. Acesso em jun.2019.

(2016). Sobrevivência das Empresas no Brasil (Out. 2016). Disponível em http://www.sebrae.com.br/Sebrae/Portal\%20Sebrae/Anexos/sobrevivencia-das-empresas-nobrasil-relatorio-2016.pdf. Acesso em jun.2019.

(2016). Mensurando a inovação: avaliação em MPES participantes do Programa Agentes Locais de Inovação / Miler Franco D'anjour e Napiê Galvê Araújo Silva (Orgs.). Natal: SEBRAE/RN.

(2018). Panorama dos Pequenos Negócios 2018. Disponível em

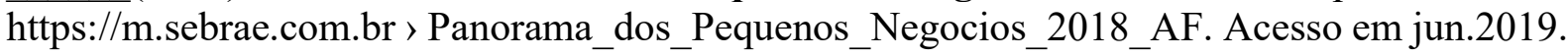

TIDD, J.; BESSANT, J.; PAVITT, K. Gestão da Inovação. Porto Alegre: Bookman, 23- 30p. 2008.

VARANDAS, A.; SALERNO, M. S.; MIGUEL, P. A. C. Análise da Gestão da Cadeia de Valor da Inovação em uma Empresa do Setor Siderúrgico. Revista Gestão \& Produção - UFSCar, v. 21, n. 1, p. 1-18, 2014.

VON HIPPEL, E.; OGAWA, S.; DE JONG, J. P. J. The age of the consumer-innovator. MIT Sloan Management Review, v.53, n.1, p.27, 2011.

WITTAYAPOOM, K. New Product Development, Accounting Information and Internal Audits: A Proposed Integrative Framework. Procedia - Social and Behavioral Sciences, V. 148, p. 307-314, 2014.

WU, J. Asymmetric Roles of Business Ties and Political Ties in Product Innovation. Journal of Business Research, V. 64, n. 11, p. 1151-1156, 2011.

ZHANG, L.; WU, B. Farmer innovation system and government intervention: An empirical study of straw utilization technology development and diffusion in China. Journal of Cleaner Production, v. 188, p. 698-707, 2018.

ZHAO, X.; PAN, W.; CHEN, L. Disentangling the relationships between business model innovation for low or zero carbon buildings and its influencing factors using structural equation modelling, Journal of Cleaner Production, v.178, p.154, 2018. 